\title{
Ensino e Aprendizagem da Matemática por Meio dos Jogos Digitais: uma Proposta Colaborativa no Laboratório de Informática
}

\section{Teaching and Learning Mathematics by Means of Digital Games: a Cooperative Proposal at the IT lab}

\author{
Lisandra Costa Pereira Kirnew*a; Luciane Guimarães Batistella Bianchinia ${ }^{\text {a }}$ Nielce Meneguelo Lobo da Costa ; \\ Luciana Michele Ventura ${ }^{a}$
}

\begin{abstract}
ânopar. Programa de Pós-Graduação Stricto Sensu em Metodologias para o Ensino de Linguagens e suas Tecnologias. PR, Brasil. bUniversidade Anhanguera de São Paulo. Programa de Pós-Graduação em Educação Matemática. SP, Brasil.

*E-mail: lisandra.kirnew@etec.sp.gov.br
\end{abstract}

\begin{abstract}
Resumo
A disciplina de Matemática é considerada difícil por muitos alunos, sobretudo para os encaminhados para atendimentos de reforço por apresentarem dificuldades que resultam em seu baixo desempenho. Um recurso atual para aprendizagem matemática está na integração deste conteúdo ao uso de tecnologias digitais, pois, além de promover diferentes possibilidades de aplicação por parte do professor, desperta o interesse dos alunos da geração atual. No entanto, na maioria das escolas que possuem computadores encontram-se professores não preparados para a integração das tecnologias aos processos de ensino e aprendizagem, restringindo-se as atividades à disciplina de Informática. Apoiado na teoria piagetiana sobre a construção do conhecimento, o presente estudo objetivou conhecer as percepções de três professores e sete alunos $\left(5^{\circ}\right.$ ano) sobre o uso dos jogos digitais e o ensino colaborativo para aprendizagem matemática. A pesquisa caracterizada como qualitativa ocorreu em quatro etapas: E1 - avaliação diagnóstica; E2 - aplicação de questionário antes da intervenção; E3 - aplicação da proposta (oito seções); e E4 - aplicação de questionário após a intervenção. Os resultados indicaram que tanto professores quanto alunos consideram efetivo o uso de jogos digitais e ensino por colaboração entre as disciplinas. Os alunos enfatizaram a experiência como divertida, diferente e legal. Concluiuse que propostas colaborativas entre os professores com o uso de tecnologias são relevantes na prática educativa e fundamentais para que o conhecimento seja construído de modo compartilhado na escola.
\end{abstract}

Palavras-chave: Ensino Colaborativo. Aula de Informática. Tecnologias digitais. Matemática.

\begin{abstract}
Mathematics is considered to be a difficult subject-matter by many students, mainly for those directed to reinforcement care due to the fact that they present difficulties resulted from their low achievement. A current resource for learning mathematics is the integration of that content with the use of digital technologies, since, besides furthering different application possibilities on the teacher's part, it arouses the interest of current generation students. However, in most of the schools which have available computers one finds out teachers who are not prepared for the integration of technologies with the processes of teaching and learning, being the activities restricted to the IT subject-matter. Based on Piaget's theory about the working up of knowledge, this study was carried out to learn about the perception of three teachers and seven students ( $5^{\text {th }}$ graders $)$ on the use of digital games and the cooperative teaching for the purpose of learning mathematics. The research characterized as a qualitative one was carried out in four phases: E1- diagnostic assessment; E2 application of a questionnaire before the intervention; E3applicationof the proposal (eight sections); and E4 - application of a questionnaire after the intervention. The results showed that both the teachers and the students considered the use of digital games and the cooperation between the subject-matters as an effective tool. The students considered the experience as funny, different and cool. One came to the conclusion that cooperative proposals carried out among teachers with the use of technologies are relevant in the educational practice and basic for the working up of knowledge fully shared in schools
\end{abstract}

Keywords: Cooperative learning. IT classroom. Digital Technologies. Mathematics.

\section{Introdução}

A educação é comumente envolvida em debates e discussões de diversos setores - públicos e privados - com o intuito de buscar estratégias efetivas para melhoria no desempenho dos alunos. Tal situação decorre de resultados, nem sempre positivos, das avaliações governamentais que geram índices da aprendizagem dos alunos, como é o caso da Prova Brasil, que avalia o desempenho dos alunos, do $5^{\circ}$ e $9^{\circ}$ ano do Ensino Fundamental e da $3^{\mathrm{a}}$ série do Ensino Médio, nas disciplinas de Língua Portuguesa e Matemática.

Com base no panorama apresentado pelos índices de avaliação da aprendizagem são geradas propostas futuras para intervenção e, no caso da Matemática, tal resultado torna- se num desafio para o professor, pelo fato de esta disciplina estar envolvida em mitos, sobretudo por parte dos alunos com dificuldades para aprendê-la.

Para esses alunos é forte a ideia de que o conhecimento matemático é difícil de ser construído e sem aplicabilidade na realidade, por isso as reações emocionais, como a falta de interesse, aumentam, como indicam pesquisas no âmbito acadêmico-científico tais como as de Carmo e Simionato (2012); Bianchini \& Vasconcelos (2014) e Kirnew, Bianchini, Ventura \& Mazzafera (2019).

Oliveira, Bianchini e Reis (2019) também pesquisaram as significações que os alunos com dificuldades em matemática, apresentaram e constataram que, na escola, são recorrentes os resultados negativos associados a mitos e crenças em relação 
a este conteúdo. Por essa razão, aventaram a necessidade de um trabalho com esses alunos, pois a Matemática não deveria ser considerada apenas como uma disciplina que ensina a fazer cálculos, uma vez que ela prepara o aluno para situações que fazem parte do seu dia a dia.

Essas reflexões suscitam a busca por novos estudos que colaborem para uma aprendizagem, na qual o aluno sinta-se interessado e compreenda a aplicabilidade deste conteúdo. O interesse, a força de vontade ou o desânimo e desinteresse são sentimentos que expressam a afetividade e estão relacionados ao processo que implica o aprender. Piaget (1978) pondera que o conhecimento é uma construção, da qual aspectos cognitivos e afetivos participam de modo indissociável, portanto, considerá-los significa obter maior compreensão de um processo complexo.

Nesse sentido, como os professores poderiam despertar o interesse dos alunos pela disciplina de matemática? Estudos como os de Belloni \& Gomes (2008), Mattar (2010), Prensky (2012), Aoki (2020) \& Ferreira et al. (2020), ajudam a responder à pergunta, pois defendem a ideia de que a aprendizagem mediada por tecnologia pode promover práticas que despertem o interesse dos alunos, uma vez que eles fazem parte de uma geração denominada por Prensky (2001) como "nativos digitais".

Prensky (2001) explica que os alunos presentes nas escolas hoje são pertencentes a uma geração tecnológica. O digital faz parte do seu cotidiano, seja pelo celular seja pelo computador, e a escola não pode ignorar este novo perfil de educandos.

Algumas escolas incluíram em sua grade curricular a disciplina de Informática, com docente próprio para ministrar essas aulas. Com isso, em sua maioria, os alunos fazem uso do computador apenas nessa disciplina, não sendo explorado pelos demais professores.

Para Kenski (2007), quando a informática é bem utilizada pelo professor, promove alterações nos seus hábitos e dos alunos, adquirindo o conhecimento e maior aperfeiçoamento do conteúdo estudado. O conteúdo a ser utilizado no computador deve ser planejado pelo professor dentro do contexto do conteúdo estabelecido para o ano/série do aluno, não apenas como entretenimento, e sim para que ocorra de fato a aprendizagem.

A interdisciplinaridade também faz parte deste processo, uma vez que permite a integração de disciplinas, partindo do princípio de que "todo conhecimento mantém um diálogo permanente com outros conhecimentos" (Brasil, 2013, p. 28).

Vale ressaltar que a informática oferece inúmeras possibilidades de aprendizagem para trabalhar as diversas disciplinas, entre elas a Matemática. Nesse contexto, Martins, Bianchini e Yaegashi (2017) destacam que uma estratégia útil para o ensino da matemática tem sido a articulação de jogos e tecnologias, como proposta promotora para despertar o interesse e a construção de novos sentidos pelos alunos.

No contexto tecnológico atual há necessidade da construção de novos sentidos para o ensino, bem como refletir sobre práticas com metodologias ativas diante das inúmeras articulações que as tecnologias promovem com o conhecimento (Bianchini, Nantes, \& Arruda, 2016, Valente, Almeida, \& Geraldini, 2017).

Diante disso questiona-se: Uma intervenção realizada por meio de jogos digitais, na aula de Informática pode promover a aprendizagem de conteúdos matemáticos?

Apoiados na teoria piagetiana sobre a construção do conhecimento, objetivou-se com este trabalho conhecer a perspectiva de professores e alunos ( $5^{\circ}$ ano) sobre o uso dos jogos digitais para o ensino e a aprendizagem da matemática, após intervenção colaborativa na aula de Informática.

\section{O Ensino da Matemática por Meio de Jogos e Tecnologias Digitais na Escola}

O uso de jogos para o desenvolvimento e a aprendizagem das crianças foi pesquisado por Piaget, pois considerava importante a atividade lúdica para a assimilação da realidade. Nas palavras do autor, "a atividade lúdica é o berço obrigatório das atividades intelectuais da criança sendo por isso, indispensável à prática educativa” (Piaget, 1998, p.14).

Piaget (1978) pondera sobre a complexidade que há na ação cognitiva em relação à construção do conhecimento, pois, para um sujeito atingir um nível mais elaborado sobre a realidade faz-se necessária a articulação de dois sistemas indispensáveis: o "fazer" e o "compreender".

Pautando-se na ideia de Piaget, Macedo (1994, p.73) explica que uma "ação física ou mental depende de dois sistemas cognitivos. Um deles é o sistema do compreender e o outro é o sistema do fazer".

Cabe destacar que entre o "fazer" e o "compreender" existe uma especificidade. Em outras palavras: o fato de praticar uma ação não significa que realmente houve apropriação (compreensão) do conhecimento. Quando o sujeito compreende uma ação, ele é capaz de procurar meios para realizar qualquer situação, ou seja, não apenas sabe o que fazer, mas como e quando deve fazer (Macedo, 1994).

Macedo (2009), estudioso dos jogos em Piaget, considera que o conhecimento é construído por meio das ações realizadas pelo sujeito quando em atividade, seja ela concreta seja abstrata. Nesse sentido, os jogos são importantes não apenas para o processo de aprendizagem na escola, mas também para a vida. Quando se joga, vários aspectos estão presentes - como a análise de estratégias, o pensar, o raciocinar, o obedecer às regras, o ganhar, o perder - e todos estes são fatores importantes e estão relacionados ao cotidiano, portanto, se bem trabalhados, permitem que o indivíduo esteja mais bem preparado para as dificuldades que porventura apareçam (Macedo, 1995).

Estudo como o de Macedo, Petty \& Passos (2007) também tem indicado uma estratégia de ensino muito útil, que é a articulação de jogos e tecnologias, como proposta 
promotora para despertar o interesse dos alunos. "O jogo promove engajamento do sujeito à ação, independentemente de ele saber ou não jogar" (Starepravo, Bianchini, Macedo, \& Vasconcelos, 2017, p. 22). Nota-se, portanto, que o ensino precisa integrar novas metodologias e que sejam ativas para incentivar os alunos nas atividades escolares, sobretudo as relacionadas aos conteúdos matemáticos.

Busarello, Bieging \& Ulbricht (2015) consideram que as tecnologias abrem novas possibilidades para que os recursos didáticos e pedagógicos sejam empregados no ensino das disciplinas, uma vez que a variedade de ferramentas e aplicativos auxilia na criação de ambientes de aprendizagem significativos ao aluno.

Nessa linha de pensamento, Levy (2009) pondera que a tecnologia digital permite aos alunos ampliar o conhecimento sobre todas as áreas, visto que existem variados softwares disponíveis para o estudo. A internet também é outra fonte colaboradora para a aprendizagem, sites informativos e interativos disponibilizam aos alunos um conhecimento real sobre diversos assuntos.

O professor, alerta Moran (2009), precisa planejar suas aulas considerando os recursos tecnológicos disponíveis, sem deixar de refletir sobre como tais recursos podem auxiliá-lo na aprendizagem de seus alunos. As atividades devem ser organizadas a fim de promover a autonomia do aluno, interação em grupo, aulas integradas ao laboratório de informática, projetos, enfim, experiências diversas promotoras do contato do aluno com a realidade.

Em relação aos jogos digitais para o ensino e a aprendizagem da matemática, Short (2012) pondera que, por seu caráter instigante, pode se tornar um convite ao aluno que, muitas vezes, apresenta dificuldades nessa disciplina levando-o a se interessar em conhecer mais sobre esse conteúdo.

Furlanetto (2013, p.52) destaca "que a organização dos processos de ensino se desenvolve a partir de atividades que satisfazem as necessidades dos alunos no processo de apropriação da cultura humana".

O professor deve refletir que existem processos mais eficientes do que outros e o uso dos jogos digitais pode ser um deles. Cabe salientar, no entanto, que a intenção em levar essa prática para a aprendizagem de um conteúdo deve ser bem planejada, e o professor precisa estar preparado para desenvolver a atividade.

Ainda em relação à intenção do professor quanto ao ensino, Bueno, Pacífico \& Pretto (2015) também alertam para o fato de que o propósito do jogo integrado ao ensino da matemática não deve ser somente de divertimento, pois, caso isso ocorra, a prática educativa acaba sendo prejudicada e os objetivos pedagógicos se perdem e descaracterizam a ação do professor.

\section{Aula de Informática Matemática: a Interdisciplinaridade como Proposta de Ensino Colaborativo na Escola}

O ensino da matemática prepara o aluno para a vida, não apenas para a realização de cálculos. Neste sentido, relacionar a matemática com a tecnologia, em especial o computador e seus softwares, pode ser colaborativo na aprendizagem do aluno

Valente (1993, p.42) relata o uso do computador como um método diferente para a aprendizagem:

o computador deve ser utilizado como um catalisador de uma mudança do paradigma educacional. Um novo paradigma que promove a aprendizagem ao invés do ensino, que coloca o controle do processo de aprendizagem nas mãos do aprendiz e que auxilia o professor a entender que a Educação não é somente a transferência de conhecimento, mas um processo de construção do conhecimento pelo aluno, como produto do seu próprio engajamento intelectual ou do aluno como um todo. O que está sendo proposto é uma nova abordagem educacional que muda o paradigma pedagógico do instrucionismo para o construcionismo.

Dessa maneira, a escola se depara com uma nova metodologia que pode ser colaboradora dos professores para a aprendizagem.

Até o momento não há uma obrigatoriedade quanto à aula de Informática para os Anos Iniciais do Ensino Fundamental, no entanto, algumas escolas a incluíram em seu currículo, em razão do crescente avanço tecnológico.

Os alunos de hoje são pertencentes a uma geração nascida com a tecnologia, denominada por Prensky (2001, p.1) de "nativos digitais". "Nossos estudantes de hoje são todos 'falantes nativos' da linguagem digital dos computadores, vídeo games e internet". O autor ainda enfatiza que "Nossos alunos mudaram radicalmente. Os alunos de hoje não são os mesmos para os quais o nosso sistema educacional foi criado"

$\mathrm{Na}$ escola, os jogos digitais podem ser colaboradores para a aprendizagem desses "nativos digitais", pois permitem construir o conhecimento por meio digital, utilizando os computadores e softwares educativos, os quais são do interesse dos alunos.

Nas escolas que possuem laboratório de informática, os professores podem fazer uso dos computadores para trabalhar as diferentes disciplinas do currículo, inovando sua prática pedagógica e despertando o interesse de seus alunos.

Ainda sobre a importância da informática, Kenski (2007, p.45) destaca que “(...) quando bem utilizada, provoca a alteração do comportamento de professores e alunos, levandoos ao conhecimento e maior aprofundamento do conteúdo estudado (...)"

Ao refletir sobre as diversas disciplinas na escola tornase relevante considerar o trabalho colaborativo entre elas para o desenvolvimento de conteúdos presentes no currículo apresentado aos alunos. As Diretrizes Curriculares Nacionais (DCN) da Educação Básica consideram a interdisciplinaridade como uma abordagem importante para a integração de disciplinas, partindo do princípio de que "todo conhecimento mantém um diálogo permanente com outros conhecimentos" (Brasil, 2013, p.28).

Para isso, há necessidade de mudanças nas práticas 
docentes, podendo a integração de disciplinas ser instrumento para uma nova metodologia. A utilização do trabalho interdisciplinar pode promover uma aprendizagem que desperte o interesse do aluno, sobretudo se for planejada de maneira a integrar as disciplinas curriculares ao uso das tecnologias digitais, por serem um recurso atual e que faz parte desta geração.

Com o avanço tecnológico, nos últimos anos, ouve-se muito sobre a necessidade em inserir tecnologias digitais na Educação. Mas o que o professor deve fazer em sala de aula em relação às tecnologias: inseri-las ou integrá-las?

Nessa linha de pensamento, Lobo da Costa \& Prado (2015. p. 102) discorrem quanto à diferença dos termos inserir e integrar: "entendemos que professor insere a tecnologia digital quando ela não provoca diferenças na aprendizagem, ou seja, a tecnologia é como se fosse um elemento estranho do fazer pedagógico".

Nas palavras de Bittar (2010, p.220), “integrar um novo instrumento em sala de aula, implica mudanças pedagógicas, mudanças do ponto de vista da visão de ensino, que devem ser estudadas e consideradas pelos professores".

No caso da integração das tecnologias ao ensino de matemática, demanda da parte do professor outros conhecimentos:

As TDIC demandam conhecimentos diversos os quais são necessários para que o professor de matemática possa "raciocinar com", "criar com" e "ensinar com" tecnologia. Ensinar, não apenas inserindo-as na sala de aula, mas integrando-as e explorando adequadamente o que elas potencializam para o ensino e a aprendizagem em Matemática (Lobo da Costa, \& Prado, 2015, p.102).

As referidas autoras destacam que o desenvolvimento das Tecnologias Digitais da Informação e Comunicação (TDIC) possibilita uma comunicação mais rápida, com a aplicação de atividades em tempo real e o compartilhamento de informações.

No entanto, esta ação exige do professor mudanças em sua prática pedagógica, sendo necessários novos conhecimentos para se apropriar das tecnologias digitais e incluí-las aos conteúdos, com ênfase aqui para a matemática (Lobo da Costa, \& Prado, 2015).

Esta pesquisa, defendeu a ideia de interdisciplinaridade entre a Matemática e a Informática, como possibilidade de reconstrução da prática pedagógica. Integrar a disciplina de Matemática, a qual para muitos é considerada de difícil aprendizagem com a aula de Informática que, por sua vez, lida com a tecnologia digital, pode ser uma prática colaborativa entre os pares envolvidos, professores e alunos, alunos e alunos, professores e professores.

\section{Método}

A pesquisa caracteriza-se como qualitativa do tipo estudo descritivo exploratório aplicado e objetivou conhecer a perspectiva de três professores e sete alunos ( $5^{\circ}$ ano), da rede municipal de ensino da cidade de Palmital - SP, sobre o uso dos jogos digitais para o ensino e aprendizagem da matemática, após intervenção colaborativa na aula de Informática.

Para a realização da pesquisa seguiu-se todos os procedimentos éticos, que envolveu desde pedido de carta de autorização da escola, Termo de Consentimento Livre e Esclarecido (TCLE) assinado pelos participantes e aprovação do Comitê de Ética em Pesquisa com Seres Humanos da UNOPAR, a qual foi concedida sob o Parecer $n^{\circ} 2.650 .393$.

Quanto à seleção dos alunos, solicitou-se a indicação das professoras responsáveis pela disciplina de Matemática (aula de reforço), por meio de uma avaliação diagnóstica, por elas realizada.

\subsection{Instrumentos de coleta e proposta intervenção}

Para coleta de dados e realização da proposta dividiu-se o estudo em quatro etapas: E1 - avaliação diagnóstica; E2 aplicação de questionário antes da intervenção; E3 - aplicação da intervenção (oito seções); e E4 - aplicação de questionário após a intervenção. A seguir o detalhamento dos instrumentos utilizados:

- Avaliação diagnóstica: o professor da sala elaborou uma prova diagnóstica para todos os alunos da sala, com conteúdo específico da disciplina, para sondagem dos conhecimentos prévios dos alunos. Com base nos resultados desta avaliação foram identificados os alunos com dificuldades do conteúdo em questão e encaminhados para a sala de reforço.

- Questionário ao professor: foram aplicados dois questionários ao professor antes e após a intervenção para verificação das percepções em relação ao trabalho colaborativo entre Informática e Matemática.

- Questionário ao aluno: dois questionários foram aplicados ao aluno antes e após a intervenção, para verificação das percepções em relação à aprendizagem mediada pelo trabalho colaborativo entre Informática e Matemática.

- Cartões para a promoção da construção do conhecimento pelo aluno: entre o fazer e o compreender. O Cartão Registro foi um recurso utilizado para auxiliar o aluno na articulação dos conteúdos, tomada de consciência e autorregulação da aprendizagem. Para isto, foram elaboradas questões promotoras de autorregulação, defendidas por Piaget e colaboradores (Piaget \& Szeminska, 1975). Promover questões autorrreguladoras implica criar perguntas que promovam o conflito de ideias e, até mesmo, a tomada de consciência de um conhecimento por parte do aluno. Com base na construção de conhecimento considerado por Piaget foram elaborados cartões com 10 perguntas desencadeadoras de reflexões sobre o conteúdo aplicado em cada encontro com os alunos. Ao responderem às questões, os alunos foram convocados a tomar consciência do conteúdo aprendido ou não, bem como a avançar em seu conhecimento para compreensões mais complexas. O objetivo era de que, além de fazer as atividades com os jogos digitais, os alunos avançassem na compreensão do conteúdo. O cartão utilizado continha, na parte da frente, a imagem do jogo e o conteúdo a ser trabalhado no dia; e, no verso, as perguntas relacionadas aos referidos conteúdos.

- Jogos digitais: Osjogos utilizados durante os encontros estavam relacionados ao conteúdo matemático, sendo encontrados nos sites Escola Games (http://www.escolagames.com.br) e Educação Dinâmica (http://www.educacaodinamica.com. br). Para cada conteúdo a ser trabalhado, foi selecionado um jogo e o nível de dificuldade. $\mathrm{Na}$ pesquisa, elegeu-se cinco 
jogos: Blocos Espaciais; Completando os Números; Material Dourado Virtual; Nunca Dez Virtual; e Tabuada do Dino. Vale ressaltar que apesar dos alunos participantes estarem no $5^{\circ}$ ano, eles não apresentaram rendimento satisfatório na avaliação diagnóstica realizada pelas professoras de matemática, e por isso foram encaminhados para aulas de reforço. Portanto os jogos escolhidos para serem trabalhados estão de acordo com a necessidade abordada pelas professoras de matemática e do reforço.

\subsection{Procedimento para análise dos resultados}

Os dados foram analisados qualitativamente, mediante análise interpretativa da intervenção com o uso de jogos digitais no laboratório de informática em relação à perspectiva dos professores e alunos sobre tais práticas e aprendizagem por meio do trabalho colaborativo entre o professor da aula do reforço e da aula de Informática.

Utilizou-se também um procedimento metodológico denominado "Nuvem de Palavras", a fim de identificar as palavras que mais apareceram nas respostas dos participantes. Este recurso permite criar, por meio de palavras, imagens e formas, diversas opções de representações gráficas de textos, de acordo com o tema do trabalho a ser realizado. As palavras que mais se repetem no texto aparecem em tamanho maior, por apresentarem relevância entre as demais, recebendo, assim, mais ênfase.

\section{Resultados}

\subsection{A aplicação da proposta}

Para a realização da proposta, inicialmente, elaborou-se um planejamento em conjunto com as professoras do $5^{\circ}$ ano e com a coordenadora, para organizar todo o material a ser utilizado na aula de Informática, a fim de se promover um trabalho colaborativo. As professoras indicaram os conteúdos que estavam trabalhando e junto com a pesquisadora investigaram (em sites da internet) quais poderiam ser os jogos digitais relativos ao conteúdo que elas trabalhavam com os alunos.

Como critério de escolha, buscou-se por jogos que trabalhavam com agrupamentos de números decimais e as quatro operações (conteúdo indicado pelas professoras). Optou-se pelos jogos encontrados nos sites Escola Games e Educação Dinâmica por serem de fácil acesso e por trazerem os objetivos do jogo com clareza. Foram selecionados para a presente intervenção cinco jogos: Blocos Espaciais, Material Dourado Virtual, Nunca Dez Virtual, Completando os Números e Tabuada do Dino.

A proposta para este estudo foi realizar uma intervenção que permitisse ao aluno construir ou melhorar seus conhecimentos na realização das quatro operações. Este procedimento foi realizado com alunos do $5^{\circ}$ ano que apresentavam dificuldades na aprendizagem de matemática.

A intervenção foi realizada em 10 encontros, sendo o primeiro e o último a aplicação dos questionários antes e após a intervenção, os outros oito encontros restantes foram destinados à aplicação dos jogos. Cada encontro teve duração de 40 minutos, divididos em cinco semanas. Foi aplicado um ou dois jogos por encontro, e ao final da aplicação dos jogos os alunos responderam alguns questionamentos sobre o desempenho que tiveram com o uso dos jogos.

No $1^{\circ}$ Encontro foi feita uma apresentação do projeto e aplicação de questionário com questões abertas e fechadas para identificar as percepções dos alunos e das professoras sobre o ensino e a aprendizagem da matemática por meio das tecnologias digitais. Do $2^{\circ}$ ao $9^{\circ}$ encontro utilizou-se o cartão registro e os jogos digitais, sendo o procedimento realizado da seguinte maneira: antes de iniciar o jogo, a pesquisadora fez alguns questionamentos sobre o conteúdo a ser trabalhado, e os participantes responderam às primeiras questões do Cartão Registro; em seguida fizeram uso do jogo digital e finalizaram respondendo às perguntas restantes. $\mathrm{O}$ objetivo da atividade foi observar os conhecimentos prévios sobre o assunto, além de saber se houve aprendizagem com o jogo. O cartão registro é composto por 10 perguntas questionadoras com o objetivo de investigar o conhecimento prévio dos alunos quanto ao conteúdo a ser trabalhado, permitindo ao aluno refletir e assimilar o que já trabalhou com a professora em sala de aula. No último encontro os participantes responderam a um questionário a fim de conhecer suas percepções após a intervenção didática com os jogos digitais. As Figuras 1 e 2 trazem um exemplo do Cartão Registro trabalhado em um dos encontros.

Figura 1 - Exemplo de Cartão Registro (frente)

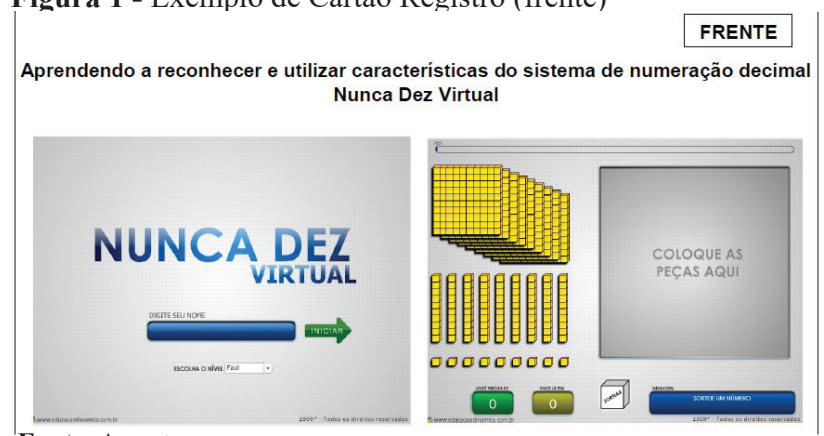

Fonte: As autoras.

Figura 2 - Exemplo de Cartão Registro (verso)

Aprendendo a reconhecer e utilizar características do sistema de numeraçäo decimal
Nunca Dez Virtual

Fonte: Dados da pesquisa. 
As questões abordadas no Cartão Registro foram todas iguais para todos os encontros, mudando apenas o nome do jogo trabalhado no encontro. Os jogos Blocos Espaciais, Material Dourado Virtual e Nunca Dez Virtual abordam o sistema de numeração decimal; o Completando os Números aborda a sequência numérica; e a Tabuada do Dino permite calcular o resultado de uma multiplicação ou divisão de números naturais.

Este instrumento de registro serviu de base para a obtenção das percepções dos alunos sobre este método de estudo. As perguntas desencadeavam mais pensamentos sobre $o$ conteúdo que estava sendo proposto no encontro, permitindo ao aluno reorganizar suas ideias, bem como identificar suas dificuldades em relação ao conteúdo matemático.

A seguir apresentam-se as percepções dos participantes por meio das questões abordadas nos questionários e do Cartão Registro aplicado aos alunos.

5.2 Percepções dos professores sobre as práticas com jogos digitais e a aprendizagem por meio do trabalho colaborativo entre professor da aula do reforço e aula de Informática

Aspectos afetivos e cognitivos se articulam a aprendizagem e, portanto sentidos negativos ou positivos podem influenciar a aprendizagem. É nessa linha que a pesquisa objetivou conhecer as percepções tanto de professores quanto alunos, após experiência com proposta de ensino colaborativo e jogos digitais para aprendizagem matemática.

A seguir, apresenta-se o relato dos dados coletados na pesquisa, as três professoras e os sete alunos serão denominados de P1, P2, P3, A1, A2, A3, A4, A5, A6 e A7, respectivamente, preservando assim, a identidade dos participantes.

Iniciou-se perguntando se houve diferença na aprendizagem de seus alunos, após a aplicação das atividades com jogos digitais e matemática. As três professoras relataram que sim. P1 destacou que "estão se empenhando e se interessando pelas aulas de Matemática"; P2 afirmou "A minha aluna ficou mais motivada"; e para P3 "eles ficaram mais atentos aos conteúdos aplicados em sala de aula".

A pergunta seguinte referia-se ao interesse dos alunos em aprender matemática por meio do jogo digital. Novamente as três professoras afirmaram positivamente. P1 relatou que "há muita ansiedade para o início da aula"; P2 destacou que "os jogos matemáticos é muito próximo da 'linguagem' dos alunos"; e P3 disse que "desperta o interesse para a aprendizagem de uma forma lúdica prazerosa".

Pode-se relacionar a resposta da professora $\mathrm{P} 2$ aos escritos de Prensky (2001), quando refere que nossos estudantes são familiarizados com os jogos digitais, destacando, ainda, a importância da sua utilização no ensino.

Quanto à proposta desta pesquisa, elas foram questionadas se consideravam relevante a intervenção com o uso de jogos digitais para o ensino da matemática. As três responderam positivamente. P1 ainda destacou que "os alunos aprendem de forma lúdica o ensino da matemática"; P2 que "é uma abordagem diferente que ampliaria o conhecimento dos alunos" e P3 afirmou que "com o uso de jogos digitais construímos uma nova realidade educacional unindo o currículo às novas tecnologias".

Observou-se, pelas respostas das professoras, que a presença do lúdico, a oportunidade de uma aprendizagem diferente, unindo a tecnologia, pode ser colaboradora para o ensino, uma vez que pode despertar o interesse dos alunos para os estudos.

A proposta dessa pesquisa também esteve relacionada à interdisciplinaridade e ao trabalho colaborativo, permitindo a interação entre as professoras das aulas de reforço e de Informática.

Durante o período da aplicação da intervenção, a professora do reforço aplicava os conteúdos a serem trabalhados na aula de Informática utilizando-se de recursos como, por exemplo, o material dourado e o jogo dominó da multiplicação. Nas aulas de Informática, os participantes realizavam os mesmos conteúdos por meio dos jogos digitais utilizando o computador.

As professoras participantes foram questionadas sobre as aulas de Informática. Foi perguntado se "durante suas aulas os alunos apresentam algum exemplo de atividade realizada na aula de informática", as respostas divergiram um pouco; apenas P1 relatou que "sim, e que os alunos relatam que as aulas em sala ficam mais fáceis", P2 afirmou que "não" e P3 não respondeu.

Perguntou-se, ainda, se elas vislumbravam a possibilidade de um trabalho colaborativo entre professora do reforço e professora de Informática. As três afirmaram positivamente, P1 ainda destacou como "uma parceria muito importante para ajudar no aprendizado matemático" e P3 justificou como "uma união perfeita, o currículo e a tecnologia".

A nuvem abaixo resume os sentidos que mais apareceram nas respostas dos professores ao tratarem do tema jogos digitais, práticas e aprendizagem por meio do trabalho colaborativo.

Figura 3 - Nuvem de Palavras - Percepções de Professores

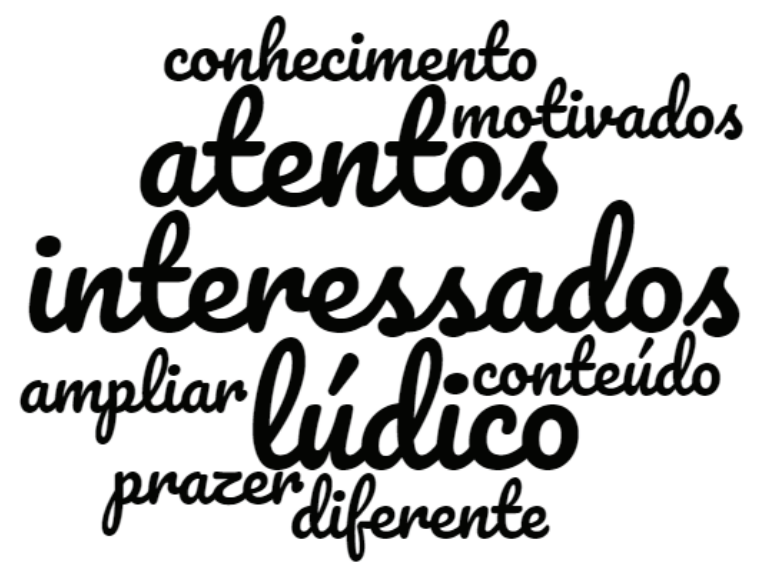

Fonte: As autoras 


\subsection{Percepções dos alunos sobre as práticas e aprendizagem por meio do trabalho colaborativo entre professor da aula do reforço e aula de Informática}

Foram realizados oito encontros no laboratório de informática da escola em que estudam, e a cada encontro foi trabalhado um ou dois jogos, sendo estes repetidos em alguns encontros, porém com nível de dificuldade maior. A cada encontro, os alunos respondiam um Cartão Registro que continha questões sobre o conteúdo e o jogo trabalhado. Este instrumento de registro serviu de base para a obtenção das percepções dos alunos sobre este método de estudo.

Durante os encontros, pôde-se observar que os alunos ficavam ansiosos e curiosos sobre o conteúdo que iriam trabalhar. Participaram das atividades com interesse e dedicação, mesmo quando tinham dificuldade para a realização das propostas.

Além do registro do cartão, a pesquisadora fez também uma observação individual, para ter uma análise melhor do rendimento dos alunos. Observou-se que alguns participantes relataram no registro não ter dificuldade e que acharam fácil, no entanto, apresentaram dificuldade na realização das atividades.

Em relação ao questionário aplicado aos alunos, iniciouse perguntando o que eles acharam de participar do projeto com o uso de jogos digitais e matemática. Todos responderam que acharam legal, bom e divertido. A2 ainda destacou "porque aprende mais"; A3 "aprende mais porque é legal e interessante"; A4 "Porque o projeto é mais legal e a matemática no computador já dá a resposta"; A6 "Muito legal uso computadores" e A7 "Legal porque usa a matemática e o jogo".

Em seguida, questionou-se quanto ao uso dos jogos digitais, se eles poderiam ajudar a aprender. Novamente todos responderam afirmativamente, destacando como legal, uma maneira diferente, divertida e que dá para aprender mais. A6 destacou "porque mostra o que erra" e A7 "porque desenvolve a imagem do jogo".

A próxima pergunta questionou se havia diferença entre aprender matemática na sala de aula sem o uso de tecnologia digital e aprender no computador com jogos digitais. Todos afirmaram que sim, destacando ser mais divertido e legal. A2 ainda relatou que "o computador me ajuda mais" e A4 "nós fazemos e já sai o resultado”.

Também foram questionados sobre o que achavam que o seu professor de Matemática precisava saber sobre a sua experiência de aprendizagem no projeto com jogos digitais. A maioria relatou que a professora poderia levá-los no laboratório de informática para utilizar o computador. Vale destacar, ainda, que A1 achou "Legal"; A2 "Ela pode trazer nós no computador"; A3 "No computador é mais fácil”; A4 "Porque ela pode vir ensinar a gente no computador"; A5 "Ela ensinar no computador porque é legal"; A6 "Ela ensinar no computador" e A7 "Material dourado pode fazer com o computador".

Pelas respostas dos alunos, observou-se que gostaram de participar do projeto, que acreditaram que o uso do jogo digital e o computador seja uma maneira diferente e divertida de aprender matemática e que a professora da sala poderia levá-los para o laboratório de informática para aprender matemática.

Uma das respostas que chamou a atenção da pesquisadora foi quando A7 respondeu "porque desenvolve a imagem do jogo". Ao ser questionada sobre o quê queria dizer com a frase, a aluna disse que "o desenho do jogo a faz pensar mais e entender o que tem que fazer".

Mais uma vez a presença do lúdico aparece como motivador do despertar o interesse para a aprendizagem.

As respostas dos participantes levaram a refletir e associar ao referencial escolhido para esta pesquisa, destacando aqui Piaget e Macedo quando se referem à importância de trabalhar com jogos para a construção do conhecimento e Prensky, Levy e Kensky, sobre o uso da tecnologia digital.

Notou-se que a dificuldade por eles encontrada não se refere ao manusear o computador ou o jogo digital, mas sim ao conteúdo, em saber como fazer, em razão da dificuldade que já apresentavam em sala de aula, por isso, participavam das aulas de reforço.

Com relação aos jogos propostos para cada encontro, os alunos relataram que não os conheciam e nunca haviam jogado. Apenas nos encontros seguintes, quando repetiram a atividade, respondiam que já haviam jogado, que é legal e divertido.

Para a pergunta relacionada às dificuldades encontradas durante a atividade com o jogo digital, as respostas foram parecidas. Alguns disseram não ter dificuldade, outros um pouco, e a grande maioria se referiu aos níveis médio e difícil. Destacaram também a dificuldade relacionada a contas, que precisavam usar os dedos.

Uma das questões abordadas "o que você precisa aprender mais sobre esse conteúdo”, a maioria das respostas foi que precisavam aprender mais. A participante A2 respondeu "nada" apenas no terceiro encontro e A7 em cinco encontros. As demais respostas foram relacionadas aos conteúdos como: "unidade, dezena e centena"; "a ordem dos números"; e "a tabuada".

As respostas permitiram inferir que o uso de jogos digitais pode ser um colaborador para a aprendizagem, sendo um método atual, lúdico e divertido, por meio do qual o aluno pode aprender brincando, tornando o estudo mais interessante.

As aulas de reforço são direcionadas para alunos que apresentam dificuldade de aprendizagem nas disciplinas de Língua Portuguesa e Matemática. Essas aulas acontecem no período de contraturno.

A proposta desse atendimento é suprir as necessidades dos alunos com relação às suas dificuldades de maneira diferenciada, como, por exemplo, pelo uso de jogos. Para Fagundes (2007), as tecnologias digitais podem colaborar de 
maneira interdisciplinar na educação.

As tecnologias digitais estão realizando transformações profundas nos processos de aprendizagem e nas mudanças da escola. Reflete que o uso das tecnologias na educação propicia a interdisciplinaridade, uma organização heterárquica, estimula a participação cooperativa e solidária, promove a autonomia e a responsabilidade da autoria nos alunos (Fagundes, 2007, p. 14).

Para essa intervenção, foi realizada uma parceria com a professora do reforço. Ela apresentava o conteúdo a ser desenvolvido com os alunos, utilizando recursos como o material dourado e jogos para, por meio desses instrumentos, os alunos aprenderem no concreto.

Nas respostas dos alunos sobre as aulas de reforço, todos afirmaram que a professora ensinou o conteúdo. O que diferenciou nos relatos foi a maneira como foram realizadas as atividades, em virtude do conteúdo a ser discutido. A maioria destacou o uso do material dourado, o caderno, o jogo dominó da multiplicação e a realização de contas.

Os alunos relataram de maneira positiva a participação das aulas de reforço antes de utilizar o jogo digital. Entre suas respostas foram elencadas algumas, tais como: "aprende mais"; "porque usei o material dourado"; "ajudou muito usar blocos"; "porque é mais legal"; "porque fiz de novo"; "porque aprende diferente"; "porque treina mais"; "tem poucas crianças por isso dá para ela prestar atenção em nós"; "é mais fácil”.

Comparando as atividades realizadas no computador por meio do jogo digital e na sala de aula, a maioria também relacionou de maneira positiva a aprendizagem com a tecnologia. Três participantes, em alguns dos encontros, disseram não ter diferença.

Destacam-se algumas respostas aleatórias referentes aos encontros: "porque é na lousa é no computador"; "porque corrige o erro"; "é mais legal”; "é diferente e porque é legal”; "é mais fácil”; "computador monta bloco"; "porque lá usa o caderno"; "porque no computador já dá a resposta"; "porque é mais legal no computador"; "no computador é só apertar os botões"; "porque aqui é mais diferente"; "eu aprendi melhor"; e "muito interessante".

Pelas respostas dos alunos, notou-se que eles gostam e sentem-se motivados em realizar a atividade no computador por meio do jogo digital. Isso remete às considerações de Short (2012), ao ponderar que em razão do jogo digital ter caráter instigante, pode despertar o interesse do aluno em aprender mais, mesmo quando apresentar dificuldade para realizar o conteúdo.

Quando perguntado "o que você aprendeu que não sabia sobre esse conteúdo", em todas as respostas referentes aos encontros, os alunos afirmaram que aprenderam. Segue algumas respostas aos conteúdos propostos: "unidade, dezena e centena"; "a ordem dos números"; "a tabuada"; "muita coisa"; "aprendi bastante"; "fazer a conta na cabeça"; e "fazer continha".

Para a questão "como foi aprender a atividade por meio do jogo", todos responderam positivamente sobre os encontros propostos. A maioria destacou ser muito bom, legal, divertido, mais fácil e que aprende mais.

Cabe destacar, também, algumas respostas aleatórias dos encontros: "sim, porque gosto de matemática e fica mais fácil para entender"; "sim gostei do jogo, no jogo é mais fácil de entender"; "sim, foi bom aprender por meio dos jogos é divertido"; "foi bom sim, eu aprendi muito"; "eu gostei porque aprendi conta"; "porque eu adorei"; e "sim, porque usa o computador".

Em suas respostas pode-se perceber que os participantes gostaram das atividades, acharam que no computador é mais fácil e aprende-se mais. A Figura 4 traz as palavras que mais apareceram nas respostas dos alunos quando expressaram suas percepções sobre o uso do jogo digital no ensino da matemática.

Figura 4 - Nuvem de Palavras - Alunos

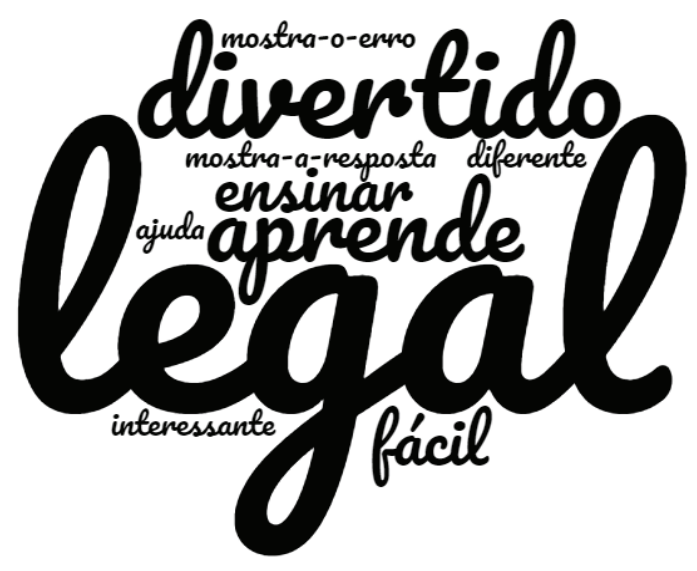

Fonte: As autoras.

Pode-se inferir, com base na nuvem de palavras, que em suas respostas os participantes gostaram das atividades, acharam que no computador é mais fácil e aprende-se mais.

\section{Considerações Finais}

O crescente uso das tecnologias digitais, em especial o computador e celular, tem alcançado novos usuários a cada dia. Crianças e adolescentes cada vez mais procuram essas mídias por diversos motivos, em especial estudo e lazer. São considerados pertencentes a uma geração denominada por Prensky (2001) de "nativos digitais". São chamados assim, pois desde cedo começam a utilizar as tecnologias e as integram ao seu cotidiano com facilidade. Diante deste perfil de usuários, faz-se necessário despertar o interesse dessa geração utilizando metodologias mais próximas do que eles vivenciam.

A maioria das crianças e adolescentes faz uso das tecnologias para jogar. É possível encontrar jogos digitais de diversos tipos e para todas as idades, e o seu uso para o ensino vem sendo discutido e incentivado por várias áreas do conhecimento. Piaget mostra, por meio de sua teoria, que o sujeito constrói o conhecimento, e o uso de jogos permite essa 
construção, uma vez que coloca o sujeito em ação enquanto joga. Dessa maneira, integrar o uso de jogos digitais ao ensino pode ser um diferencial para a educação, visto se tratar de um recurso lúdico, atual e do interesse desta geração.

Com relação ao processo de ensino e aprendizagem, pesquisas levantadas no início deste trabalho possibilitaram duas reflexões: uma sobre a aula de Informática e outra sobre a disciplina de Matemática.

Os resultados indicaram que a Matemática é uma das disciplinas que apresentam desafios ao professor, pois carrega mitos por parte dos alunos, como a de que se trata de um conteúdo difícil. Sobre a Informática, autores ponderam que muitas vezes, nos laboratórios, são realizados trabalhos desarticulados com as demais disciplinas e os alunos têm a ideia de que este espaço é para realização de atividades lúdicas.

As percepções das professoras, após a intervenção, estavam de acordo com a literatura selecionada para este estudo, pois relataram que a presença do lúdico, a oportunidade de uma aprendizagem diferente, unindo a tecnologia, pode ser colaboradora para o ensino, com o intuito de despertar o interesse dos alunos para os estudos.

Nas percepções dos alunos, eles indicaram o uso de jogos como legal, bom e divertido, além de ser uma maneira diferente de aprender matemática. Consideraram o uso do computador e os jogos digitais como facilitadores para a aprendizagem, sendo um método atual, lúdico e divertido, por meio do qual o aluno pode aprender brincando, tornando o estudo mais interessante. As dificuldades por eles apresentadas estavam relacionadas ao conteúdo trabalhado em si, mas passou a ser possível de compreensão justamente pelo caráter promotor da ação cognitiva que o jogo convoca.

Outro aspecto importante nessa intervenção foi o uso do Cartão Registro, pois, por meio dele, os alunos puderam reorganizar suas ideias bem como identificar suas dificuldades em relação ao conteúdo matemático, à medida que respondiam às questões apresentadas a eles e construíam conhecimento. $\mathrm{O}$ conhecimento é construído, para Piaget, em articulação com os diversos conteúdos; nesse sentido, vale refletir sobre a sua fragmentação na escola, de modo que muitos alunos não conseguem transpô-lo para sua realidade.

Embora na pesquisa houvesse uma preocupação em realizar a intervenção colaborativa entre as disciplinas de Matemática e Informática, conclui-se que a colaboração pode ser estendida para várias outras, Matemática e Física, Matemática e Ciências, etc.

O ensino por colaboração entre as disciplinas pode ser um meio de o aluno construir conhecimento de modo complexo, significativo e com continuidade das atividades realizadas em diferentes contextos. Por isso sugere-se que novos estudos sejam desenvolvidos sobre essa temática que envolve jogos digitais e o ensino colaborativo entre as disciplinas.

\section{Referências}

Aoki, R. (2020). Aprendizagem baseada em Jogos Digitais aplicada ao ensino de Redação Jornalística. Media \& Jornalismo, 20(36), 109-128.

Belloni, M. L., \& Gomes, N. G. (2008). Infância, mídias e aprendizagem: autodidaxia e colaboração. Educação \& Sociedade, 29(104), 717-746.

Bianchini, L. G. B., Nantes, E. A. S., \& Arruda, R. B. (2016). Processos de instrumentalização da leitura e escrita na era midiática: da decodificação à ubiquidade do leitor. Blucher Social Sciences Proceedings, 2(4), 553-561.

Bianchini, L. G. B., \& Vasconcelos, M. S. (2014). Significação e sentimentos dos alunos quando erram na matemática. Psicologia da Educação, 38, 63-71.

Bittar, M. (2010). A Escolha do Software Educacional e a Proposta Didática do Professor: estudo de alguns exemplos em matemática. In W. Beline, N. M., \& Lobo da Costa (Orgs.), Educação Matemática, tecnologia e formação de professores: algumas reflexões (pp. 215-242). Campo Mourão FECILCAM.

Brasil. (2013). Secretaria de Educação Básica. Diretrizes Curriculares. Brasília: MEC/SEB/DICEI.

Bueno, J. L. P., Pacífico, J. M., \& Pretto, N. L. (2015). Tecnologias na Educação: políticas, práticas e formação docente. Florianópolis: Pandion.

Busarello, R. I., Bieging, P., \& Ulbricht, V. R. (2015). Sobre Educação e Tecnologia. São Paulo: Pimenta Cultural.

Carmo, J. do S., \& Simionato, A. M. (2012). Reversão de ansiedade à matemática: alguns dados da literatura. Psicologia em Estudo, 17(2), 317-327.

Fagundes, L. (2007). O professor deve tornar-se um construtor de inovações - entrevista. Midiativa. Disponível em http:// www.midiativa.org.br/index.php/educadores/layout/set/ print/content/view/full/1053/

Ferreira, M., Silva Filho, O. L., Moreira, M. A., Franz, G. B., Portugal, K O., \& Nogueira, D. X. P. (2020). Unidade de Ensino Potencialmente Significativa sobre óptica geométrica apoiada por vídeos, aplicativos e jogos para smartphones. Revista Brasileira de Ensino de Física, 42, e20200057.

Furlanetto, F. R. (2013). O movimento de mudança de sentido pessoal na formação inicial do professor. (Tese de doutorado, Faculdade de Educação, Universidade de São Paulo).

Kirnew, L. C. P., Bianchini, L. G. B., Ventura, L. M., \& Mazzafera, B. L. (2019). Jogos digitais no ensino da matemática: um estudo bibliométrico. Revista Ciências \& Ideias, 10, 107-118.

Kenski, V. M. (2007). Educação e Tecnologias: o novo ritmo da informação. Campinas: Papirus. (Coleção Papirus Educação).

Lévy, P. (2009). Cibercultura. São Paulo: Editora 34.

Lobo da Costa, N. M., \& Prado, M. E. B. B. (2015). A Integração das Tecnologias Digitais ao Ensino de Matemática: desafio constante no cotidiano escolar do professor. Perspectivas $d a$ Educação Matemática, 8(16), 99-120.

Macedo, L. (1994). Ensaios Construtivistas: Para uma visão construtivista do erro no contexto escolar. São Paulo: Casa do Psicólogo.

Macedo, L. (Org.). (2009). Jogos, Psicologia e Educação: teoria e pesquisas. São Paulo: Casa do Psicólogo.

Macedo, L. (1995). Os jogos e sua importância na escola. Cadernos de Pesquisa, (93), 5-10. 
Macedo, L., Petty, A. L. S., \& Passos, N. C. (2007). Os Jogos e o Lúdico na Aprendizagem Escolar. Porto Alegre: Artmed.

Martins, A., Bianchini, L. G. B., \& Yaegashi, S. F. R. (2017). Webquest e a afetividade presente na construção de conhecimento matemático por alunos do ensino médio. Bolema, 31(57), 289-309.

Mattar, J. (2010). Games em educação: como os nativos digitais aprendem. São Paulo: Pearson Prentice Hall.

Moran, J. M. (2009). Novas Tecnologias e Mediação Pedagógica. Campinas: Papirus.

Oliveira, F. N., Bianchini, L. G. B., \& Reis, L. A. (2019) Significações do professor e indicadores de resiliência em estudantes com dificuldades de aprendizagem em matemática. ETD: Educação Temática Digital, 21, 416-434.

Piaget, J., \& Szeminska, A. (1975). A gênese do número na criança. Rio de Janeiro: Zahar.

Piaget, J. (1978). Psicologia e Epistemologia: por uma teoria do conhecimento. Rio de Janeiro: Forense Universitária.

Piaget, J. (1998). A Psicologia da criança. Rio de Janeiro: Bertrand Brasil.
Prensky, M. (2001). Nativos digitais, imigrantes digitais. On the horizon, 9(5), 1-6.

Prensky, M. (2012) Aprendizagem baseada em jogos digitais. São Paulo: Senac.

Short, D. (2012). Teaching scientific concepts using a virtual worls - Minecraft. Teching Science 58(3), 55-58.

Starepravo, A. R., Bianchini, L. G. B., Macedo, L. \& Vasconcelos, M. S. (2017). Autorregulação e situação problema no jogo: estratégias para ensinar multiplicação. Psicologia Escolar $e$ Educacional, 21(1), 21-31.

Valente, J. A. (1993). Por que o Computador na Educação. In J. A. Valente (Org.), Computadores e Conhecimento: Repensando a Educação (pp. 24-44). Campinas: NIED/UNICAMP.

Valente, J., Almeida, M. E. B., \& Geraldini, A. F. S. (2017). Metodologias ativas: das concepções às práticas em distintos níveis de ensino. Revista Diálogo Educacional, 17(52), 455478 .

Wordclouds. Nuvem de Palavras. Disponível em: https://www. wordclouds.com/. Acesso em: 03 out. 2019. 